\title{
Effect of a second layer on the time to failure of compressed riprap as mountain riverbank protection
}

\author{
Mona Jafarnejad, Mário J. Franca, Michael Pfister \& Anton J. Schleiss
}

To cite this article: Mona Jafarnejad, Mário J. Franca, Michael Pfister \& Anton J. Schleiss (2019) Effect of a second layer on the time to failure of compressed riprap as mountain riverbank protection, Journal of Hydraulic Research, 57:4, 573-578, DOI: 10.1080/00221686.2018.1494048

To link to this article: https://doi.org/10.1080/00221686.2018.1494048

Published online: 17 Sep 2018.

Submit your article to this journal $₫$

Џ Article views: 73

View Crossmark data $\complement$ 
Technical Note

\title{
Effect of a second layer on the time to failure of compressed riprap as mountain riverbank protection
}

\author{
MONA JAFARNEJAD, Researcher, Laboratory of Hydraulic Constructions (LCH), École Polytechnique Fédérale de Lausanne \\ (EPFL), Lausanne, Switzerland \\ Email: mona.jafarnejad@epfl.ch (author for correspondence)
}

MÁRIO J. FRANCA*, (IAHR Member), Research and Teaching Associate, Laboratory of Hydraulic Constructions (LCH), École Polytechnique Fédérale de Lausanne, Lausanne, Switzerland

Email:m.franca@un-ihe.org

MICHAEL PFISTER**, (IAHR Member), Research and Teaching Associate, Laboratory of Hydraulic Constructions (LCH), École Polytechnique Fédérale de Lausanne (EPFL), Lausanne, Switzerland

ANTON J. SCHLEISS (D) (IAHR Member), Professor, Laboratory of Hydraulic Constructions (LCH), École Polytechnique Fédérale de Lausanne (EPFL), Lausanne, Switzerland

Email: anton.schleiss@epfl.ch

\begin{abstract}
Recently, Jafarnejad, Franca, Pfister, and Schleiss [2017. Time-based failure analysis of compressed riverbank riprap. Journal of Hydraulic Research, 55(2), 224-235. doi:10.1080/00221686.2016.1212940] presented an experimental study on the stability of compressed riprap, which means that it is composed of individually placed blocks with a single layer as riverbank protection. The relationship between the time to failure and dimensionless bed shear stress was presented. Here, the authors complement the previous investigation with results regarding the effect of a second riprap layer. In total, 49 tests ( 28 tests with one and 21 tests with two riprap layers) were performed using a single block size, three longitudinal channel slopes and three different riprap bank inclinations. Under similar conditions, the second layer can significantly delay the time to failure, whereas the block erosion rate was found to increase. The second layer has a more stabilizing role when the bank angle of the riprap is approaching the angle of repose of the blocks.
\end{abstract}

Keywords: Riprap; double layer; time to failure; riverbank protection; stability

\section{Introduction}

There are several methods available for the design of dumped riprap as riverbank protection (Jafarnejad, Pfister, Brühwiler, \& Schleiss, 2017). However, few studies have been performed focusing on the effect of riprap thickness on riverbank stability. Maynord, Ruff, and Abt (1989) performed a limited number of experiments to evaluate the thickness effect and reported a stability criterion. For relatively low-turbulence applications such as riverbank protection, USACE (1994) specifies a minimum thickness of $D_{100}$ or $1.5 D_{50}$, whichever is greater. Escarameia
(1998) recommends a minimum thickness of 2D $\mathrm{D}_{50}$. Experimentally, Abt et al. (1988) and Maynord et al. (1989) revealed that any additional thickness above these minima augments the stability. Consequently, multiple layers of small blocks may sometimes provide an equivalent stability to one single layer of large blocks. The increase in stability with riprap thickness (number of layers) is substantial for wide block gradations but is relatively low for uniform gradations (Maynord \& Neill, 2008). The improvement in stability with increasing thickness can be explained by redundancy if more material is available. In other words, more energy is needed to expose

Received 10 April 2017; accepted 19 June 2018/Open for discussion until 29 February 2020.

*Currently Professor of Hydraulic Engineering and River Basin, Water Science and Engineering Department, IHE Delft Institute for Water Education, Delft, the Netherlands

**Currently Professor, Research and Teaching Associate, Civil Engineering Department, Haute Ecole d'Ingénierie et d'Architecture (HEIA-FR, HES-SO), 1705 Fribourg, Switzerland 


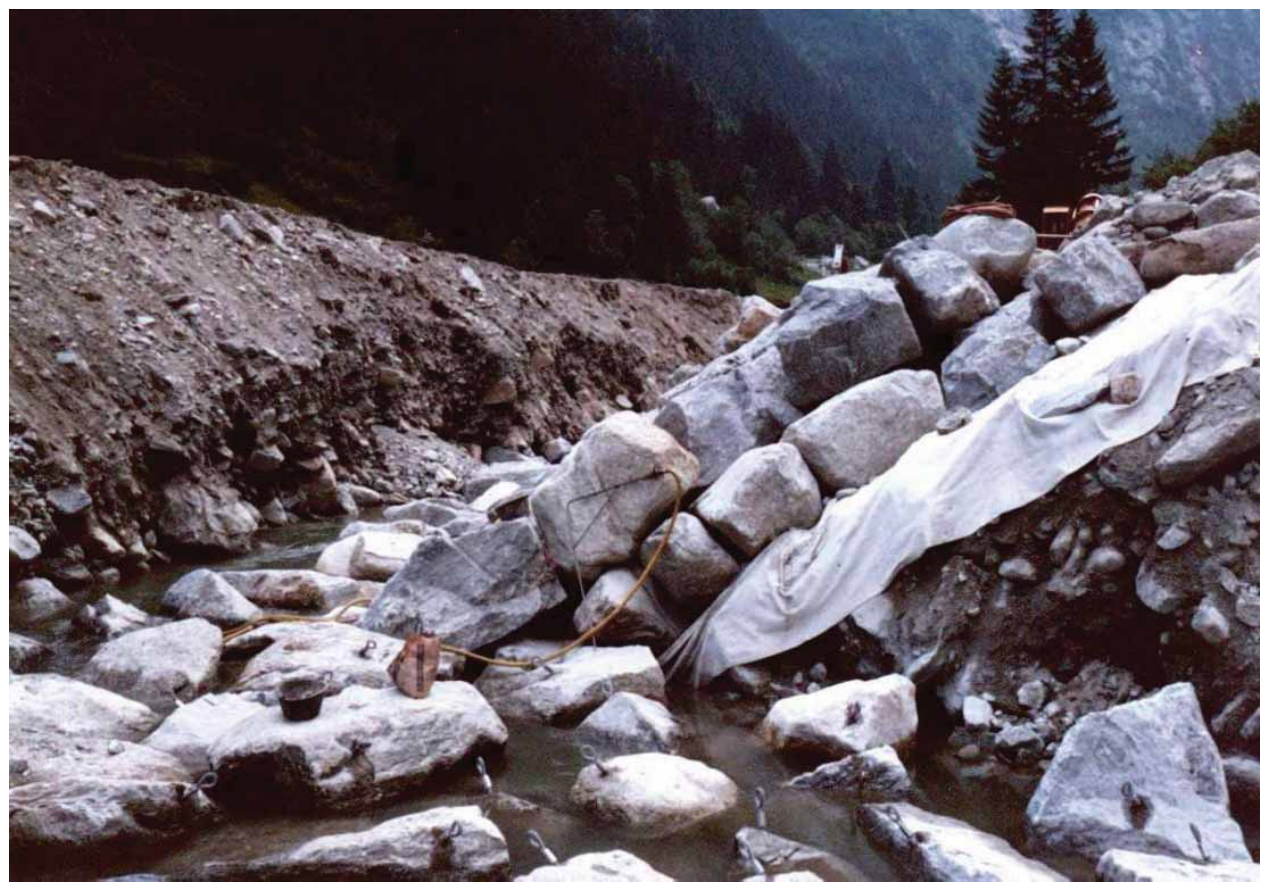

Figure 1 Riprap on the Reuss River in Switzerland under construction with individually placed large blocks in two layers on a geotextile. Block weight is $4.0-4.5$ t. (Courtesy of A.J. Schleiss)

the filter and the natural soil underlying the blocks (Simons, 1995).

In alpine rivers with high bed slopes, the design of riprap bank protection results in large, heavy blocks $(>1 \mathrm{t})$ that have to be placed individually due to their weight. A study on the stability of such riprap with individually placed large blocks, also called compressed or packed riprap, was presented by Jafarnejad, Franca, Pfister, and Schleiss (2017). The weight of the individually placed blocks is limited to a maximum of approximately $5 \mathrm{t}$ to $7 \mathrm{t}$ due to handling and the availability from quarries (Schleiss, 2000). If the design of the riprap results in very large blocks that cannot be handled or are not available, in practice, the riprap may be built with double layers in order to obtain better safety protection (Fig. 1). Nevertheless, no design criteria exist for riprap with two layers of individually placed blocks. The additional safety gain due to a second layer is unknown. Thus, in the framework of a systematic research study on compressed or packed riprap (Jafarnejad, 2016), 21 new test series using a double layer were performed and compared to the initial 28 one-layer tests. Thus, in total, 49 tests with similar conditions are available, with either one or two riprap layers. The following analysis focuses on the characteristic time to failure and the critical hydraulic parameters for the occurrence of complete failure. The main goal is to evaluate the role of the second layer regarding time to failure of the riverbank riprap protection.

\section{Experimental set-up and procedure}

The 49 systematic experiments were performed in a flume with longitudinal slopes of $1.5 \%, 3 \%$ and $5.5 \%$ for both one and two layers (Table 1). The transversal riprap bank inclinations were varied at $2.5 \mathrm{~V}-5 \mathrm{H}\left(27^{\circ}\right), 3 \mathrm{~V}-5 \mathrm{H}\left(31^{\circ}\right)$, and $3.5 \mathrm{~V}-5 \mathrm{H}\left(35^{\circ}\right)$, as they occur in prototype riprap using individually placed large blocks. The laboratory riprap material consisted of uniform crushed stones with a representative diameter of $\mathrm{D}_{50}=0.037 \mathrm{~m}$. The discharge was kept constant for a maximum of $3 \mathrm{~h}$ for each experiment. Lower discharges may cause direct block erosion during the experiments but not a full failure of the bank inclination. Higher discharges result in very fast full bank failure. The tests were carried out under supercritical and uniform flow conditions in the flume. More detailed information on the experimental procedures can be found in Jafarnejad, Franca, et al. (2017).

\section{Temporal analysis of failure}

In Jafarnejad, Franca, et al. (2017), a time-dependent analysis was performed, where the time to total failure of the riprap was investigated based on the evolution of the block transport rate measured at a section downstream of the riprap protection. Here, the same analysis is performed to investigate the time delay caused by the presence of a second layer of riprap. The effects of the discharge, the channel longitudinal slope and the riprap bank inclination are taken into account.

Figure 2 shows the time evolution of the riprap-block transport rate measured at the downstream section of the channel for a longitudinal channel slope of 3\% and for different unit discharges and various riprap bank inclinations. The total failure of a bank section corresponds to a sudden asymptotic increase in the number of eroded blocks. 
Table 1 Experiments run for one- and two-layered riprap protection. In the column corresponding to the time to failure, $t_{f}$, the tests where no failure occurred during the test are indicated

\begin{tabular}{|c|c|c|c|c|c|c|}
\hline Series & $\begin{array}{l}\text { Number of } \\
\text { layers }\end{array}$ & $\begin{array}{c}\text { Slope of } \\
\text { channel (\%) }\end{array}$ & $\begin{array}{l}\text { Inclination } \\
\text { of riprap }\left(^{\circ}\right)\end{array}$ & $q\left(\mathrm{~m}^{2} \mathrm{~s}^{-1}\right)$ & $h(\mathrm{~m})$ & $t_{f}(\min )$ \\
\hline 1 & 1 & 0.015 & 35 & 0.287 & 0.187 & No failure \\
\hline 2 & 1 & 0.015 & 35 & 0.303 & 0.197 & 172 \\
\hline 3 & 1 & 0.015 & 35 & 0.314 & 0.202 & 87 \\
\hline 4 & 1 & 0.015 & 35 & 0.330 & 0.209 & 43 \\
\hline 5 & 1 & 0.015 & 35 & 0.360 & 0.190 & 9 \\
\hline 6 & 2 & 0.015 & 35 & 0.392 & 0.233 & No failure \\
\hline 7 & 2 & 0.015 & 35 & 0.400 & 0.235 & 165 \\
\hline 8 & 2 & 0.015 & 35 & 0.408 & 0.239 & 73 \\
\hline 9 & 2 & 0.015 & 35 & 0.433 & 0.248 & 10 \\
\hline 10 & 1 & 0.030 & 35 & 0.210 & 0.122 & No failure \\
\hline 11 & 1 & 0.030 & 35 & 0.244 & 0.134 & No failure \\
\hline 12 & 1 & 0.030 & 35 & 0.251 & 0.136 & No failure \\
\hline 13 & 1 & 0.030 & 35 & 0.263 & 0.141 & 94 \\
\hline 14 & 1 & 0.030 & 35 & 0.281 & 0.145 & 73 \\
\hline 15 & 1 & 0.030 & 35 & 0.301 & 0.165 & 62 \\
\hline 16 & 1 & 0.030 & 35 & 0.313 & 0.167 & 12 \\
\hline 17 & 2 & 0.030 & 35 & 0.280 & 0.150 & No failure \\
\hline 18 & 2 & 0.030 & 35 & 0.299 & 0.163 & 161 \\
\hline 19 & 2 & 0.030 & 35 & 0.313 & 0.168 & 102 \\
\hline 20 & 2 & 0.030 & 35 & 0.332 & 0.182 & 23 \\
\hline 21 & 1 & 0.030 & 31 & 0.209 & 0.126 & No failure \\
\hline 22 & 1 & 0.030 & 31 & 0.230 & 0.134 & 143 \\
\hline 23 & 1 & 0.030 & 31 & 0.314 & 0.147 & 27 \\
\hline 24 & 1 & 0.030 & 31 & 0.345 & 0.170 & 3 \\
\hline 25 & 2 & 0.030 & 31 & 0.239 & 0.132 & No failure \\
\hline 26 & 2 & 0.030 & 31 & 0.245 & 0.140 & 137 \\
\hline 27 & 2 & 0.030 & 31 & 0.316 & 0.151 & 78 \\
\hline 28 & 2 & 0.030 & 31 & 0.359 & 0.167 & 14 \\
\hline 29 & 1 & 0.030 & 27 & 0.186 & 0.118 & No failure \\
\hline 30 & 1 & 0.030 & 27 & 0.212 & 0.129 & No failure \\
\hline 31 & 1 & 0.030 & 27 & 0.233 & 0.137 & No failure \\
\hline 32 & 1 & 0.030 & 27 & 0.247 & 0.142 & No failure \\
\hline 33 & 1 & 0.030 & 27 & 0.258 & 0.146 & 172 \\
\hline 34 & 1 & 0.030 & 27 & 0.268 & 0.150 & 44 \\
\hline 35 & 1 & 0.030 & 27 & 0.301 & 0.157 & 33 \\
\hline 36 & 1 & 0.030 & 27 & 0.344 & 0.170 & 17 \\
\hline 37 & 2 & 0.030 & 27 & 0.258 & 0.145 & No failure \\
\hline 38 & 2 & 0.030 & 27 & 0.301 & 0.157 & 92 \\
\hline 39 & 2 & 0.030 & 27 & 0.320 & 0.162 & 44 \\
\hline 40 & 2 & 0.030 & 27 & 0.344 & 0.170 & 21 \\
\hline 41 & 1 & 0.055 & 35 & 0.202 & 0.100 & No failure \\
\hline 42 & 1 & 0.055 & 35 & 0.235 & 0.109 & 120 \\
\hline 43 & 1 & 0.055 & 35 & 0.255 & 0.117 & 42 \\
\hline 44 & 1 & 0.055 & 35 & 0.273 & 0.122 & 4 \\
\hline 45 & 2 & 0.055 & 35 & 0.231 & 0.109 & No failure \\
\hline 46 & 2 & 0.055 & 35 & 0.255 & 0.117 & 146 \\
\hline 47 & 2 & 0.055 & 35 & 0.273 & 0.122 & 101 \\
\hline 48 & 2 & 0.055 & 35 & 0.291 & 0.127 & 62 \\
\hline 49 & 2 & 0.055 & 35 & 0.307 & 0.138 & 11 \\
\hline
\end{tabular}

Although all shown unit discharges provoke a failure for the single and double-layered riprap protection systems, the results indicate that the second layer of riprap significantly delays the time to failure. However, as shown in Fig. 1a and 1b, an increase in the unit discharge reduces the relative enhancement of the failure delay provided by the second layer. This indicates that the use of a two-layered riprap as bank protection becomes relatively less effective under increasing discharges. In other words, there is a limit to the advantage of two riprap bank layers in postponing the failure. 

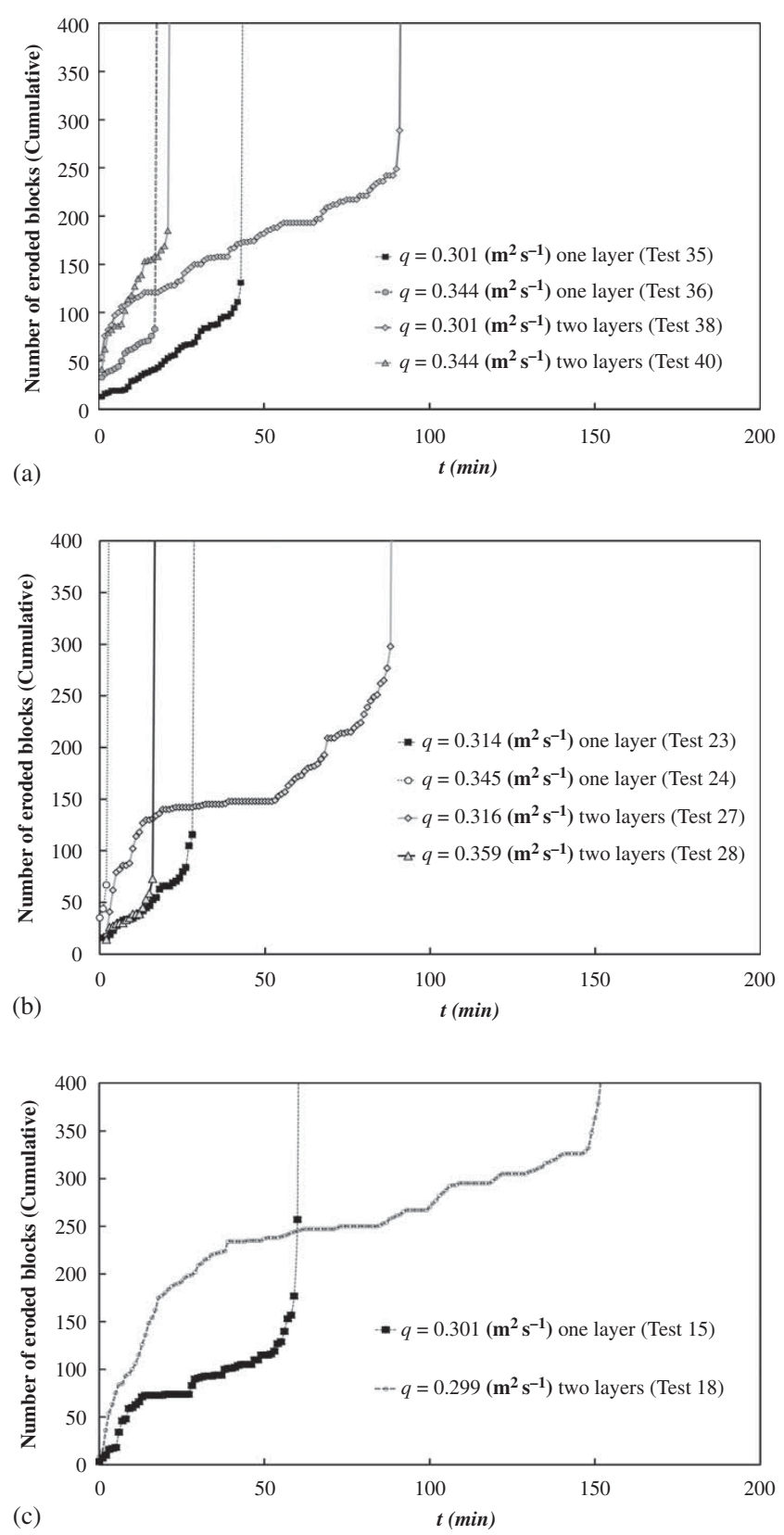

Figure 2 Time evolution of the cumulative block erosion rate for a channel slope of 3\% comparing one layer and two layers of riprap: (a) riprap inclination of $27^{\circ}$; (b) riprap inclination of $31^{\circ}$; and (c) riprap inclination of $35^{\circ}$

Furthermore, Fig. 2 reveals that the failure with a second layer occurs later for higher bank inclinations. Therefore, the time to failure becomes longer with increasing bank inclination. For the lower unit discharge of $0.301 \mathrm{~m}^{2} \mathrm{~s}^{-1}$ in Fig. 2a, with a bank inclination of $27^{\circ}$, the increase in the time to failure is approximately $100 \%$ due to the second riprap layer. For the same unit discharge and a bank inclination of $35^{\circ}$, the second layer increases the time to failure by a factor of approximately three compared to the one layer riprap, as seen in Fig. 2c. Nevertheless, the comparison of the time to failure of one- and two-layered riprap for the highest longitudinal channel slope of

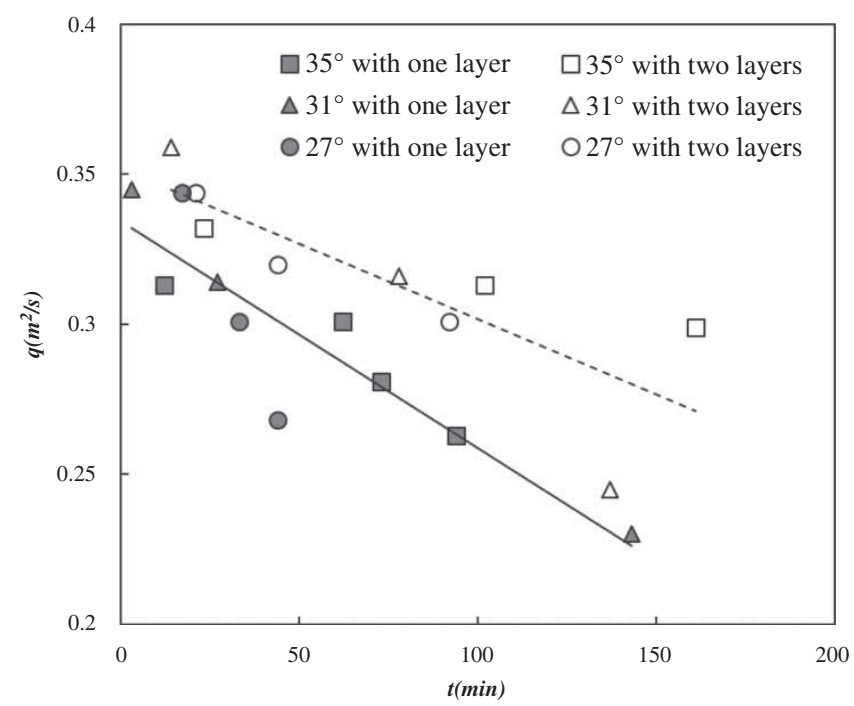

Figure 3 Time to failure of one- and two-layered riprap (continuous and dashed trend lines, respectively) as a function of unit discharge and three different bank inclinations of $27^{\circ}, 31^{\circ}$, and $35^{\circ}$ for a channel slope of $3 \%$. Only the tests where failure was observed are represented

$5.5 \%$ (Table 1 ) shows a delay of only $10 \%$ in the time to failure. Thus, the delaying effect of the riprap with a second layer becomes less important when compared to the lower longitudinal channel slopes $(\leq 3 \%)$. In Table 1 , all the tests with and without failure are included. It can be clearly noticed that the use of two-layered riprap not only considerably delays the time to failure but also increases the resistance of the protection against the erosive action of the flow.

To analyse the effect of bank inclination, the time to failure of one- and double-layered riprap are shown in Fig. 3 for different unit discharges for three different bank inclinations of $27^{\circ}, 31^{\circ}$ and $35^{\circ}$. The results of approximately 20 series experiments for the channel slope of $3 \%$ clearly reveal that the second layer of large blocks postpones the failure for all tested bank inclinations. Nevertheless, the postponing effect of the second block layer decreases with increasing unit discharges for all tested bank inclinations. The bank inclination of the riprap, especially in steep channels, has a clear effect on the riprap stability (Jafarnejad, 2016). However, when the failure happens, the time to failure is somewhat random. No clear trend in the time to failure as a function of bank inclination can be seen (Fig. 3). Nevertheless, steeper riprap has higher interlocking forces between the blocks that may cause a longer time to failure for certain cases. That may be the reason for a bank with an inclination of $27^{\circ}$ (Fig. 2a) failing faster than a bank with an inclination of $35^{\circ}$ for a unit discharge of $q=0.301 \mathrm{~m}^{2} \mathrm{~s}^{-1}$ (Fig. 2c). However, independent from the bank inclination, Fig. 3 shows the effect of two-layered riprap.

\section{Parameterization of the time to failure}

Figure 4 shows the dimensionless time to failure $T^{*}{ }_{h}$ as a function of the dimensionless bed shear stress $\tau^{*}$. The latter 

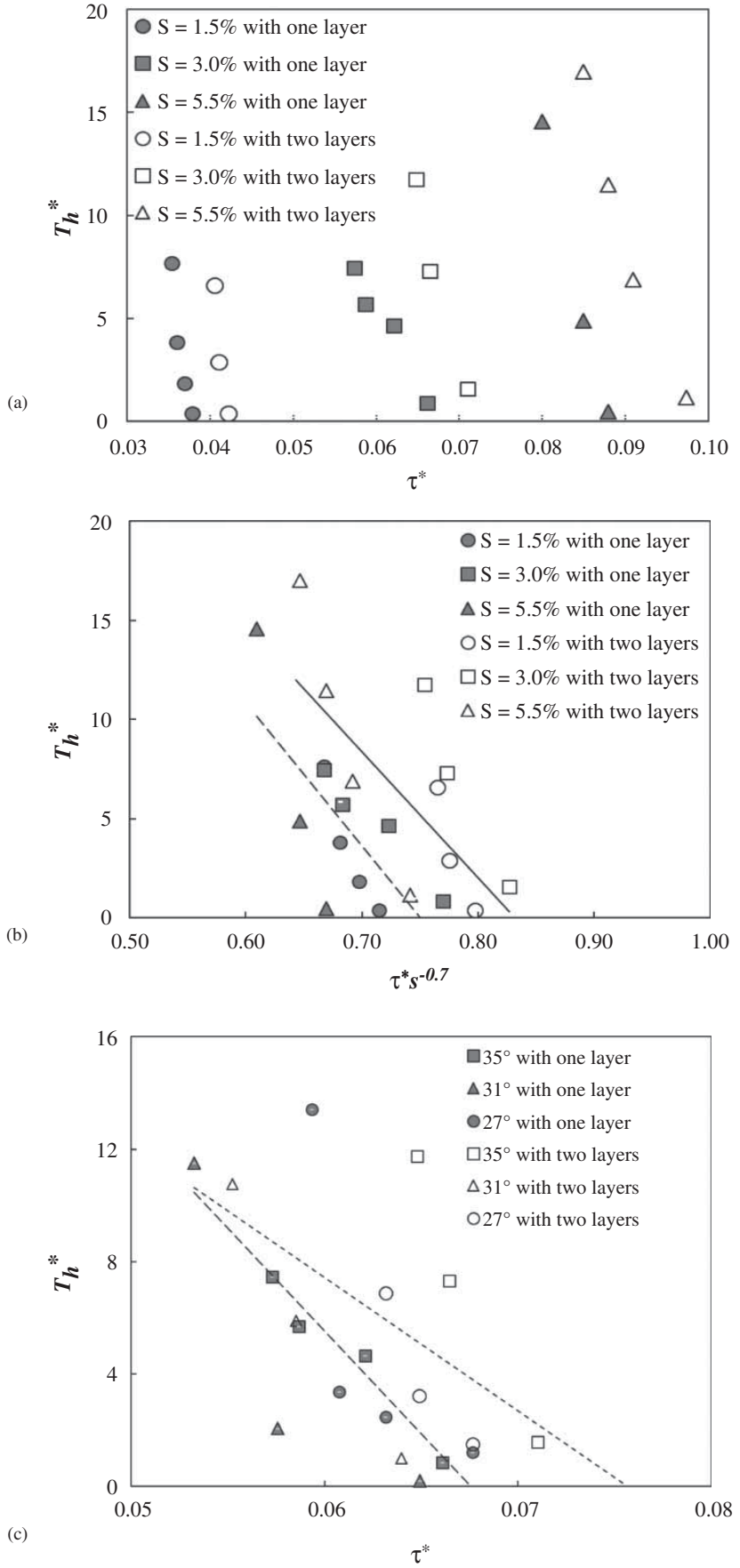

Figure 4 Dimensionless failure time $\left(T^{*} h\right)$ as a function of the following: (a) dimensionless bed shear stress $\tau^{*}$ for a riprap inclination of $35^{\circ}$ grouped by channel slopes $S=1.5 \%, 3 \%$ and $5.5 \%$; (b) dimensionless bed shear stress considering channel slope defined as $\tau * S^{-0.7}$ for a riprap inclination of $35^{\circ}$ grouped by slopes $S=1.5 \%, 3 \%$ and $5.5 \%$ (the straight lines correspond to linear regressions applied to the results with single- (dashed line) and double-layered (continuous line) riprap; and (c) dimensionless bed shear stress $\left(\tau^{*}\right)$ for the three riprap bank inclinations of $27^{\circ}, 31^{\circ}$ and $35^{\circ}$ and channel longitudinal slope of $3 \%$. Only the tests where failure was observed are represented

represents the balance of hydrodynamic forces acting on the riprap and the submerged weight of the blocks. Both values are calculated as proposed by Jafarnejad, Franca, et al. (2017).
In Fig. $4 \mathrm{a}$ and $4 \mathrm{~b}$, tests with the same bank inclination of $35^{\circ}$ for three longitudinal channel slopes are shown. The channel slope $S$ has a significant effect on the time to failure of the riverbank riprap, especially in steep mountain rivers where very high shear stress occurs mainly at the toe of the riprap (Jafarnejad, Franca, et al. 2017). As expected, the time to failure increases with the reduction in the bed shear stress. When grouped by slope, a linear fit is found between $T^{*}{ }_{h}$ and $\tau^{*}$ for one-layer $\left(R^{2} \approx 0.92,0.95\right.$ and 0.99 for $S=1.5 \%, 3 \%$ and $5.5 \%$, respectively) and two-layer ( $R^{2} \approx 0.89,0.96$ and 0.96 for $S=1.5 \%$, $3 \%$ and $5.5 \%$, respectively) tests. The results also suggest that the normalization of the time to failure considering the flow depth on a geometrical scale is appropriate.

Figure $4 \mathrm{a}$ reveals that the dimensionless time to failure depends on the longitudinal channel slope $S$. Accordingly, the dimensionless bed shear and the longitudinal slope are taken into account to describe the dimensionless time to failure. If considering $\tau * S^{-0.7}$, as proposed by Jafarnejad, Franca, et al. (2017), a good agreement among the different slope values $S$ is found. In Fig. 4b, the data points are clearly grouped for the riprap with one and two layers for all longitudinal slopes. The delay in the time to failure provoked by a second riprap layer is clearly visible.

For a channel longitudinal slope of $3 \%$, the time to failure is shown in Fig. 4c as a function of the dimensionless shear stress $\tau *$ for different tested riprap bank inclinations and for singleand double-layered riprap. For the lower riprap bank inclinations $\left(27^{\circ}\right.$ and $\left.31^{\circ}\right)$, there is only a slight failure delay due to the second layer of protection. However, for the maximum tested bank inclination of $35^{\circ}$, the delay in failure resulting from the second layer is significant compared to the other tested bank inclinations (Fig. 4c). The angle of repose of the blocks used in the laboratory is $41^{\circ}$. Considering this angle, it seems that for the same channel slope, the stabilizing role of the second layer becomes more important if the riprap bank inclination becomes steeper and approaches the angle of repose. As mentioned before, for a steeper bank inclination, the interlocking forces between the blocks due to their weight are higher, which especially postpones the failure. The second layer has an important role in postponing the exposure of the filter behind the riprap to the flow and consequently total failure.

\section{Conclusions}

The effect of a second layer of riprap with compressed, individually placed blocks on its stability was experimentally investigated. Generally, a second layer stabilizes the bank and can significantly postpone failure. However, the block erosion rate is significantly increased.

The use of a two-layered riprap becomes less effective on delaying failure if the unit discharge or channel slope increases. Furthermore, the delay of failure is more significant for steeper bank inclinations since a second layer of the riprap provides 
better protection when approaching the angle of repose of the blocks.

\section{Funding}

This research was funded by the Swiss Federal Office for the Environment (FOEN) [contract number A2111.0239/10-Q8 0019.PJ/J372-1192].

\section{Notation}

$D=$ block size $(\mathrm{m})$

$D_{50}=$ median diameter of spherical blocks $(\mathrm{m})$

$D_{100}=$ largest diameter of spherical blocks (m)

$h \quad=$ flow depth $(\mathrm{m})$

$q=$ unit discharge $\left(\mathrm{m}^{2} \mathrm{~s}^{-1}\right)$

$S=$ longitudinal channel slope $(-)$

$t=$ time (s)

$t_{f}=$ time to failure (min)

$T_{h}{ }^{*}=$ normalized time to failure characterizing flow depth (-)

$\tau^{*}=$ dimensionless bed shear stress $(-)$

\section{ORCID}

Anton J. Schleiss (D) http://orcid.org/0000-0003-1559-5740

\section{References}

Abt, S. R., Wittler, R. J., Ruff, J. F., LaGrone, D. L., Khattak, M. S., Nelson, J. D., ... Lee, D. W. (1988). Development of riprap design criteria by riprap testing in flumes: Phase II, Followup investigations. NUREG/CR-4651, ORNL/TM10100/V2, Vol. 2, prepared for U.S. Nuclear Regulatory Commission, Washington, D.C., Colorado State University,
Fort Collins, Colo., and Oak Ridge National Laboratory, Oak Ridge, Tenn.

Escarameia, M. (1998). River and channel revetments, a design manual. London: Thomas Telford.

Jafarnejad, M. (2016). Time-dependent failure analysis of large block size riprap as bank protection in mountain rivers $(\mathrm{PhD}$ thesis). EPFL No. 6803 and Communication 62, Laboratory of hydraulic constructions (LCH), Lausanne, Ed. A. Schleiss, ISSN 1661-1179.

Jafarnejad, M., Franca, M. J., Pfister, M., \& Schleiss, A. J. (2017). Time-based failure analysis of compressed riverbank riprap. Journal of Hydraulic Research, 55(2), 224-235. doi:10.1080/00221686.2016.1212940

Jafarnejad, M., Pfister, M., Brühwiler, E., \& Schleiss, A. J. (2017). Probabilistic failure analysis of riprap as riverbank protection under flood uncertainties. Stochastic Environmental Research and Risk Assessment, 31(7), 1839-185. doi:10.1007/s00477-016-1368-6

Maynord, S. T., Ruff, J. F., \& Abt, S. R. (1989). Riprap design. Journal of Hydraulic Engineering, 115(7), 937-949.

Maynord, S. T., \& Neill, C. (2008). Riprap Design. In M. H. García (Ed.), Sedimentation Engineering (pp. 1037-1056). ASCE Manual and Reports on Engineering Practice No. 110. Reston, VA: American Society of Civil Engineering. doi:10.1061/9780784408148

Schleiss, A. (2000). Design and landscape integration of riprap in mountain rivers (in German). Proc. of the Int. Symposium Interpraevent 2000, Villach, Austria. Band 2, pp. 351-360.

Simons, D. B. (1995). Fundamental concepts of riprap use for channel stabilization. In C. R. Thorne, S. R. Abt, F. B. J. Barends, S. T. Maynord, \& K. W. Pilarczyk (Eds.), River, coastal and shoreline protection, erosion control using riprap and armor stone (pp. 3-16). New York, NY: Wiley.

US Army Corps of Engineers (USACE). (1994). Hydraulic design of flood control channels. EM 1110-2-1601. US Government Printing Office, Washington, DC. 